\section{Effects of rhythmic}

auditory stimulation

on functionality in Parkinson's disease

\author{
Repercussões da estimulação \\ auditiva rítmica sobre a \\ funcionalidade na doença \\ de Parkinson
}

Izaura Muniz Azevedo (10*

Ihana Thaís Guerra de Oliveira Gondim (i)

Kássia Maria Clemente da Silva (D)

Cleysiane de Araujo Oliveira (1)

Carla Cabral dos Santos Accioly Lins (D)

Maria das Graças Wanderley de Sales Coriolano (D)

Universidade Federal de Pernambuco (UFPE), Recife, PE, Brazil

Date of first submission: November 10, 2020

Last received: April 19, 2021

Accepted: May 20, 2021

Associate editor: Ana Paula Cunha Loureiro

* Correspondence: ihanafisio@hotmail.com

\section{Abstract}

Introduction: Functionality is affected by the clinical characteristics and progression of Parkinson's disease (PD).

Objective: Assess the effects of a therapeutic exercise program associated with music-based rhythmic auditory stimulation (RAS) on the Activities and Participation Profile (APP) related to mobility of people with PD. Methods: Intervention study investigating people with moderate PD recruited from the Hospital das Clínicas of the Federal University of Pernambuco and the Parkinson's Disease Association of Pernambuco. The APP related to mobility of the participants was assessed based on the International Classification of Functioning Disability and Health (ICF). The APP contains 23 activity/participation items scored from 0 (no problem) to 4 (complete problem). The intervention consisted of 10 outpatient sessions of a therapeutic exercise program associated with music-based RAS, applied using a smartphone application (ParkinSONS ${ }^{\circledR}$ ), performed twice a week, with an average duration of 50 minutes per session. Given the metric nature of the variable and its non-normal distribution, Wilcoxon's test was applied, considering $p$ $<0.05$. Results: In the sample of 8 patients, there was a significant decline in APP scores after intervention ( $p=$ $0.018^{\star}$ ), indicating a positive change. Scores for all the APP activities decreased following the intervention, except for "transferring oneself to the left side while lying down". Conclusion: In this study, a therapeutic exercise program associated with music-based RAS had a positive effect on the APP related to mobility of people with moderate PD.

Keywords: Auditory stimulation. ICF. Music. Parkinson's disease. Physiotherapy. 


\section{Resumo}

Introdução: A funcionalidade é afetada pelas características clínicas e progressão da doença de Parkinson (DP). Objetivo: Avaliar as repercussões da aplicação de um protocolo de fisioterapia motora associado à estimulação auditiva rítmica (EAR) com música sobre o perfil de atividade e participação $(P A P)$ relacionado à mobilidade de pessoas com DP. Métodos: Estudo de intervenção realizado com pessoas em estágio moderado de DP recrutadas no Hospital das Clínicas da Universidade Federal de Pernambuco e na Associação de Parkinson de Pernambuco. Estas foram avaliadas e reavaliadas mediante o PAP relacionado à mobilidade baseado na Classificação Internacional de Funcionalidade, Incapacidade e Saúde (CIF). O PAP apresenta 23 itens de atividades/ participação pontuados entre $O$ (não há problema) e 4 (problema completo). A intervenção consistiu de 10 sessões ambulatoriais de fisioterapia motora associada à EAR com música fornecida por aplicativo instalado em smartphone (ParkinSONS ${ }^{\circledR}$ ) duas vezes por semana, com duração média de 50 minutos por sessão. Devido à natureza métrica da variável e sua distribuição não normal, aplicou-se o teste de Wilcoxon, considerando $p<0.05$. Resultados: Na amostra de oito pacientes, O PAP apresentou uma redução significativa dos escores após a intervenção $\left(p=0.018^{*}\right)$, indicando mudança positiva no perfil. Todas as atividades do PAP apresentaram diminuição do escore após a intervenção, exceto "transferir-se para o lado esquerdo enquanto estiver deitado". Conclusão: Neste estudo, a aplicação de um protocolo de fisioterapia motora associada à EAR com música em pessoas no estágio moderado da DP apresentou repercussões positivas sobre o $P A P$ relacionado à mobilidade baseado na CIF.

Palavras-chave: Estimulação acústica. CIF. Música. Doença de Parkinson. Fisioterapia.

\section{Introduction}

The functionality of people with Parkinson's disease (PD) is affected by a number of impairments triggered by the disorder, such as bradykinesia, rigidity, resting tremor and postural instability. Additionally, discomfort such as aching, cramps and joint pain, and difficulties with motor coordination, transfers, mobility, postural control and the ability to perform activities of daily living can emerge over time as the disease worsens. ${ }^{1,2}$
According to the International Classification of Functioning Disability and Health (ICF), functioning refers to all body functions, activities and participation, while disability is an umbrella term for impairments, activity limitations and participation restrictions. Environmental factors interact with these components and are key to determining the functioning/disability of the individual, since they represent barriers or facilitators. ${ }^{3,4}$

People with PD who take part in exercise programs showed improved physical function and performance in activities related to functional mobility, muscle strength, endurance, coordination, flexibility, balance and walking, resulting in better perceived quality of life when compared to physically inactive patients. ${ }^{5-7}$

Physiotherapists use a series of techniques aimed at transfers, posture, upper limb function, balance and gait training and functional capacity, as well as activities that require cognitive and motor skills, in order to improve independence, safety and well-being. ${ }^{6,8}$ In PD, the goal of physiotherapy is to maximize functional capacity through movement rehabilitation. ${ }^{9}$

Rhythmic auditory stimulation (RAS) with music is increasingly being used as a tool in functional rehabilitation, capable of promoting physiological changes, neuroplasticity and neural circuit reconstruction, thereby contributing to the recovery of motor skills in neurological patients. Research on the performance of the auditory system and rhythmic synchronization in motor control showed synchronization between the auditory and motor systems. ${ }^{10-13}$

Music has the ability to be engaging, emotional, personal, physical, social and persuasive, in addition to promoting movement synchronization, making it a relaxing and enjoyable therapeutic tool. It also provides motor, cognitive, psychosocial and behavioral benefits for people with neurological disorders such as PD, and should be included in multidisciplinary programs aimed at functionality. ${ }^{14-16}$

Individualized RAS approaches using mobile technology such as smartphone applications may be a safe and economical alternative for outpatient and home-based rehabilitation in patients with PD. However, the apps currently available are still lacking in terms of providing individualized stimulation suited to the task, with rhythm increases calculated to improve performance. ${ }^{17,18}$

No studies were found that assess the effects of physiotherapy protocols associated with music-based 
RAS on the Activities and Participation Profile (APP) related to mobility in people with PD. As such, the aim of this study was to evaluate the effects of a therapeutic exercise program associated with music-based rhythmic auditory stimulation on the APP related to mobility of people with PD.

\section{Methods}

This is a preliminary before-and-after study. The non-probabilistic (convenience) sample consisted of people aged $\geq 50$ years, of both sexes, with a clinical diagnosis of idiopathic PD. The diagnosis was in line with the Parkinson's UK Brain Bank Criteria stipulated in Ordinance 10/2017 of the Brazilian Ministry of Health, ${ }^{19}$ and confirmed by the presence of clinically assessed bradykinesia (a necessary criterion), muscular rigidity and/or resting tremor $(4-6 \mathrm{~Hz})$, combined with at least three positive supporting criteria. ${ }^{19}$ Included were people with moderate PD (stages HY2 and HY3), according to the original version of the Hoehn and Yahr (HY) scale. ${ }^{20}$ The original version of the scale classifies patients into five stages: HY1 - unilateral involvement only, with little or no functional impairment; HY2 - bilateral or axial involvement, without balance impairment; HY3 - mild to moderate bilateral disease, with some postural instability and physically independent; HY4 - severe disability, but still able to walk or stand unassisted; HY 5 - wheelchair bound or bedridden unless aided.

All the patients were recruited from the Pro-Parkinson Program of the Hospital das Clínicas of the Universidade Federal de Pernambuco (HC/UFPE) and the Parkinson's Disease Association of Pernambuco, between May and October 2019. The study was conducted in accordance with National Health Council/Ministry of Health (CNS/MS) Resolution 466, of December 12, 2012, ${ }^{21}$ and approved by the Research Ethics Committee of the Universidade Federal de Pernambuco's Health Sciences Center (CAAE $\left.n^{\circ} 01548918.2 .0000 .5208\right)$. All the participants provided written informed consent.

Excluded were those with other neurological, orthopedic, rheumatological and/or vascular disorders that affected gait or made it impossible to walk for 10 meters unaided; amputees; lower limb prostheses and orthotics; self-reported hearing difficulties preventing them from hearing music or a conversation; uncontrolled high blood pressure; contraindication for physical exercises by the assistant physician; cognitive impairment identified by the Mini-Mental State Examination (MMSE) according to schooling level, ${ }^{22,23}$ and severe depression based on the Beck Depression Inventory. ${ }^{24}$

The assessment was conducted in the so-called "on" phase ( $1 \mathrm{~h}$ after taking medication) and involved recording personal and clinical information on a "sociodemographic/clinical data form", including the patient's full name, telephone number, address, schooling level, degree of dependence in activities of daily living, side of the body where initial symptoms emerged, medication used, with doses and times, and other information related to the eligibility criteria. Next, the APP was assessed based on a selection of 23 activity/ participation items related to mobility from Chapter 4 of the $\mathrm{ICF}^{25}$ that reflect the logic of neural development (Figure 1).

Each item is scored from 0 to 4, as follows: 0 - "no problem" (0-4\%); 1 - "mild problem" (5-24\%); 2 "moderate problem" (25-49\%); 3 - "severe problem" (50-95\%); 4 - "complete problem" (96-100\%); 8 - "not specified"; 9 - "not applicable". The sum of the scores for the items ranges from 0 to 100 , and the final score is obtained by dividing by the number of items. ${ }^{25}$

The APP is related to functioning from both an individual and social perspective. The term activity refers to the execution of a task or action by an individual and participation is their involvement in a life situation. ${ }^{3}$

The participants underwent 10 outpatient sessions of therapeutic exercises associated with music-based RAS, applied using a smartphone application (ParkinSONS ${ }^{\circledR}$ ), twice a week, with an average duration of 50 minutes per session.

The therapeutic exercise program was based on the Portuguese version of the European Physiotherapy Guideline for Parkinson's Disease, which aims to standardize evidence-based physiotherapy. ${ }^{26}$ It was applied at two levels of difficulty, with complexity modified from the sixth session onwards. Of the nine therapeutic exercises, RAS was associated with the four that could be performed naturally to a beat (Figure 2).

The ParkinSONS ${ }^{\circledR}$ application provides a menu of gait training options and functional activities with RAS containing six Brazilian songs whose tempo varies from 70 to $120 \mathrm{bpm}$, which can be accompanied by a metronome. The app uses a smartphone touchscreen interface, facilitating clear and objective user interaction. 


\begin{tabular}{|c|c|}
\hline \multicolumn{2}{|c|}{ Activity and Participation Profile (APP) related to mobility based on ICF } \\
\hline \multicolumn{2}{|c|}{ Name: } \\
\hline 1. Sitting & $\mathrm{d} 4103-\mathrm{xxx} .0($ ) xxx.1( ) xxx.2( ) xxx.3( ) xxx.4() \\
\hline 2. Lying down & $\mathrm{d} 4100-\mathrm{xxx} .0($ ) xxx.1( ) xxx.2( ) xxx.3( ) xxx.4() \\
\hline 3. Rolling over & $\mathrm{d} 4107-\mathrm{xxx} .0($ ) xxx.1( ) xxx.2( ) xxx.3( ) xxx.4( ) \\
\hline 3.1 To the right & $\mathrm{d} 4107-\mathrm{xxx} .0() \times x x .1() \times x x .2() \times x \times .3() \times x x .4()$ \\
\hline 3.2 To the left & d4107-xxx.0( ) xxx.1( ) xxx.2( ) xxx.3( ) xxx.4( ) \\
\hline 4. 4. Transferring oneself while lying down & d4201-xxx.0( ) xxx.1( ) xxx.2( ) xxx.3( ) xxx.4() \\
\hline 4.1 To the right & d4201 - xxx.0( ) xxx.1( ) xxx.2( ) xxx.3() xxx.4() \\
\hline 4.2 To the left & d4201-xxx.0( )xxx.1( )xxx.2( )xxx.3( ) xxx.4( ) \\
\hline 5. Crawling & d4550 - xxx.0( ) xxx.1( ) xxx.2( ) xxx.3( ) xxx.4() \\
\hline 6. Kneeling & d4102-xxx.0( ) xxx.1( ) xxx.2( )xxx.3( ) xxx.4( ) \\
\hline 7. Bending & $\mathrm{d} 4105-\mathrm{xxx} .0($ ) xxx.1( ) xxx.2( ) xxx.3( ) xxx.4( ) \\
\hline 8. Transferring oneself while sitting & d4200-xxx.0( ) xxx.1( ) xxx.2( ) xxx.3( ) xxx.4() \\
\hline 9. Standing & d4104-xxx.0( )xxx.1( ) xxx.2( )xxx.3( )xxx.4( ) \\
\hline 10. Squatting & d4101-xxx.0( )xxx.1( )xxx.2( )xxx.3( )xxx.4() \\
\hline 11. Kicking & d4351-xxx.0( ) xxx.1( ) xxx.2( ) xxx.3( ) xxx.4( ) \\
\hline 12. Pushing with lower extremities & d4350 - xxx.0( )xxx.1( ) xxx.2( )xxx.3( )xxx.4( ) \\
\hline 13. Walking short distances & $\mathrm{d} 4500-\mathrm{xxx} .0($ ) xxx.1( ) xxx.2( ) xxx.3( ) xxx.4( ) \\
\hline 14. Walking long distances & d4501-xxx.0( ) xxx.1( ) xxx.2( ) xxx.3( ) xxx.4() \\
\hline 15. Walking on different surfaces & d4502-xxx.0( ) xxx.1( ) xxx.2( ) xxx.3( ) xxx.4() \\
\hline 16. Walking around obstacles & d4503-xxx.0( ) xxx.1( ) xxx.2( )xxx.3( ) xxx.4() \\
\hline 17. Climbing & d4551-xxx.0( )xxx.1( )xxx.2( )xxx.3( )xxx.4() \\
\hline 18. Moving around within the home & d4600-xxx.0( ) xxx.1( ) xxx.2( ) xxx.3( ) xxx.4() \\
\hline 19. Moving around within buildings other than home & d4601-xxx.0( )xxx.1( )xxx.2( )xxx.3( )xxx.4() \\
\hline 20. Moving around outside the home and other buildings & d4602-xxx.0( ) xxx.1( ) xxx.2( ) xxx.3( ) xxx.4() \\
\hline 21. Using private motorized transportation & d4701-xxx.0( ) xxx.1( ) xxx.2( ) xxx.3( ) xxx.4( ) \\
\hline 22. Using public motorized transportation & d4701-xxx.0( )xxx.1( ) xxx.2( ) xxx.3() xxx.4() \\
\hline 23. Driving motorized vehicles & $\begin{array}{l}\mathrm{d} 4751-\mathrm{xxx} .0(\text { ) xxx.1( ) xxx.2( )xxx.3( ) xxx.4( ) } \\
\text { xxx.8( )xxx.9() }\end{array}$ \\
\hline
\end{tabular}

\footnotetext{
Generic classification scale

xxx.0. No problem - none, absent, negligible (0 - 4\%).

$x x x .1$. Mild problem - slight, low $(5-24 \%)$ - uses strategies and/or compensates.

xxx.2. Moderate problem - medium, fair (25 - 49\%) - needs some assistance.

xxx.3. Severe problem - high, extreme (50 - 95\%) - capable, but needs significant assistance.

xxx.4. Complete problem ( $96-100 \%)$ - incapable, even with significant assistance.

$x x x .8$. Not specified - although the problem exists, it cannot be classified.

xxx.9. Not applicable.
}

Figure 1 - Evaluation of the Activity and Participation Profile (APP) of people with moderate stage of Parkinson's disease, based on chapter 4 of the International Classification of Functioning Disability and Health (ICF). 


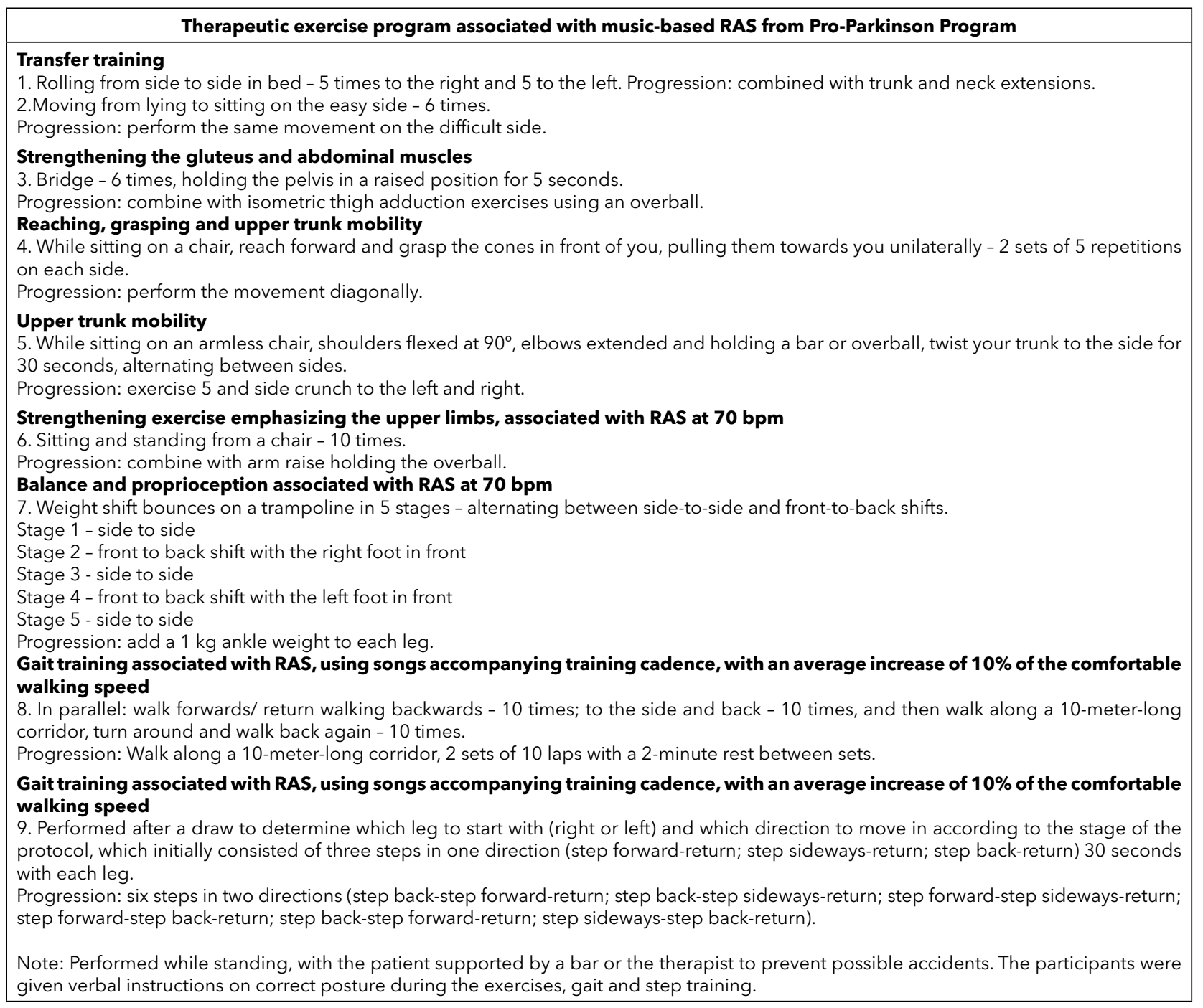

Figure 2 - "Pro-Parkinson" motor physical therapy protocol associated with rhythmic auditory stimulation (RAS) applied to patients with moderate stage of Parkinson's disease.

Songs with a tempo of $70 \mathrm{bpm}$ were used for the strength and balance exercises, and songs with an average increase of $10 \%$ of the comfortable walking speed for gait and step training. In the case of gait, comfortable walking speed was determined based on cadence, represented by the number of steps taken in the time needed to walk a certain distance. To that end, the 10-meter walk test was used to determine the number of steps and time taken to walk comfortably along a 10-meter-long corridor, with markers placed at 2 and 8 $m$ to signal the points for acceleration and deceleration, considering only the 6 central meters for calculation purposes. One evaluator was responsible for counting the number of steps taken over the $6 \mathrm{~m}$ considered and another for establishing the time needed to do so. The timer was activated and stopped when the patient's hallux touched the 2 and $8 \mathrm{~m}$ marks, respectively. Three tests were performed and the average was calculated. These data (steps and time) were used to calculate the speed and baseline cadence of the patients. The cadence measurements were converted by multiplying the time in seconds by 60 to obtain the steps/per minutes. ${ }^{27}$

Once the appropriate song had been chosen, the phone was connected to the headphones worn simultaneously by the patient and therapist, allowing the training session to be monitored at the selected tempo. All the participants were given verbal instructions to execute the movements in time with the music and, 
when necessary, demonstrations were performed by the researchers. The volume of the music was approximately $75 \mathrm{~dB}$, well above the threshold perceived by older adults with hearing loss, namely 25 to $40 \mathrm{~dB} \cdot{ }^{28}$ The assessment and treatment were carried out by the same professionals.

The data were tabulated using descriptive statistics and expressed as mean, standard deviation and variation (minimum and maximum value). Given the metric nature of the variable and non-normal data distribution, paired comparison was performed using the Wilcoxon test at $p$ $<0.05$. The statistical package used was BioEstat5.0.

\section{Results}

Sixteen patients were recruited and eight excluded (seven for not meeting the eligibility criteria and one for withdrawing from the intervention in session 8 due to a domestic accident). The final sample consisted of eight patients, most of whom were male and in stage HY2 of the disease. The symptoms of the majority of patients began on the right side of the body (Table 1).

In relation to the APP scores obtained at assessment, participants were classified as "mild problem" in 14 of the 23 items. At reassessment, only the item "transferring oneself to the left while lying down" maintained this classification. All the remaining APP items that obtained "problem" at assessment were categorized as "no problem" after the intervention (Table 2).

Scores varied from 0 to 2 ("no problem" to "moderate problem") for most of the items. Scores for "transferring oneself to the right and left while lying down", "transferring oneself while sitting" and "squatting" ranged from 0 to 3 ("no problem" to "severe problem"). Only the scores for "walking long distances" varied between 0 and 4 ("no problem" to "complete problem"). Six patients (75\%) were attributed a score of 9 (not applicable") for "driving motorized vehicles" and none of the APP items received a score of 8 ("not specified") (Table 2).

Table 1 - Personal and clinical characteristics of the sample ( $n=8$ patients)

\begin{tabular}{|c|c|}
\hline Personal variables & n (\%) \\
\hline \multicolumn{2}{|l|}{ Age (years) } \\
\hline$\geq 60$ & $6(75)$ \\
\hline $51-59$ & $2(25)$ \\
\hline \multicolumn{2}{|l|}{ Sex } \\
\hline Male & $5(63)$ \\
\hline Female & $3(37)$ \\
\hline Clinical variables related to eligibility & Mean (standard deviation) \\
\hline Mini-Mental State Examination & $29(02)$ \\
\hline Beck Depression Inventory & $11(10)$ \\
\hline Clinical variables related to Parkinson's disease & n (\%) \\
\hline \multicolumn{2}{|l|}{ Disease stage } \\
\hline HY2 & $5(63)$ \\
\hline HY3 & $3(37)$ \\
\hline \multicolumn{2}{|l|}{ Disease duration (years)* } \\
\hline 1 a 5 & $2(25)$ \\
\hline 6 a 10 & $5(63)$ \\
\hline$>10$ & $1(12)$ \\
\hline \multicolumn{2}{|l|}{ Side of symptom onset } \\
\hline Right & $6(75)$ \\
\hline Left & $2(25)$ \\
\hline
\end{tabular}

Note: *Time intervals according to supporting criteria positive for PD. ${ }^{19} \mathrm{HY}=$ stages of the original Hoehn and Yahr scale. 
Tabela 2 - Activity and participation profile (APP) scores before and after the intervention ( $n=8$ patients)

\begin{tabular}{|c|c|c|c|c|c|c|}
\hline \multirow[t]{2}{*}{ APP item } & \multicolumn{3}{|c|}{$\begin{array}{l}\text { Assessment } \\
\text { (before intervention) }\end{array}$} & \multicolumn{3}{|c|}{$\begin{array}{c}\text { Reassessment } \\
\text { (after intervention) }\end{array}$} \\
\hline & $\begin{array}{c}\text { Score } \\
\mathbf{x}( \pm)\end{array}$ & Min-Max & Interpretation & $\begin{array}{l}\text { Score } x \\
( \pm)\end{array}$ & Min-Max & Interpretation \\
\hline 1. Sitting & $0(0)$ & $0-1$ & No problem & $0(0)$ & $0-1$ & No problema \\
\hline 2. Lying down & $1(1)$ & $0-2$ & Mild problem & $0(0)$ & $0-1$ & No problem \\
\hline \multicolumn{7}{|l|}{ 3. Roling over } \\
\hline 3.1 To the right & $0(1)$ & $0-1$ & No problem & $0(0)$ & $0-1$ & No problem \\
\hline 3.2 To the left & $1(1)$ & $0-2$ & Mild problem & $0(0)$ & $0-1$ & No problem \\
\hline \multicolumn{7}{|l|}{ 4. 2. Transferring oneself while lying down } \\
\hline 4.1 To the right & $1(1)$ & $0-3$ & Mild problem & $0(1)$ & $0-1$ & No problem \\
\hline 4.2 To the left & $1(1)$ & $0-3$ & Mild problem & $1(1)$ & $0-1$ & Mild problem \\
\hline 5. Crawling & $1(1)$ & $0-2$ & Mild problem & $0(0)$ & $0-1$ & No problem \\
\hline 6. Kneeling & $0(1)$ & $0-1$ & No problem & $0(0)$ & $0-0$ & No problem \\
\hline 7. Bending & $1(1)$ & $0-2$ & Mild problem & $0(0)$ & $0-1$ & No problem \\
\hline 8. Transferring oneself while sitting & $1(1)$ & $0-3$ & Mild problem & $0(0)$ & $0-1$ & No problem \\
\hline 9. Standing & $1(1)$ & $0-2$ & Mild problem & $0(0)$ & $0-0$ & No problem \\
\hline 10. Squatting & $1(1)$ & $0-3$ & Mild problem & $0(0)$ & $0-1$ & No problem \\
\hline 11. Kicking & $0(0)$ & $0-1$ & No problem & $0(0)$ & $0-0$ & No problem \\
\hline 12. Pushing with lower extremities & $1(1)$ & $0-1$ & Mild problem & $0(0)$ & $0-1$ & No problem \\
\hline 13. Walking short distances & $0(0)$ & $0-1$ & No problem & $0(0)$ & $0-0$ & No problem \\
\hline 14. Walking long distances & $1(1)$ & $0-4$ & Mild problem & $0(0)$ & $0-1$ & No problem \\
\hline 15. Walking on different surfaces & $0(1)$ & $0-2$ & No problem & $0(0)$ & $0-0$ & No problem \\
\hline 16. Walking around obstacles & $0(1)$ & $0-1$ & No problem & $0(0)$ & $0-1$ & No problem \\
\hline 17. Climbing & $0(1)$ & $0-2$ & No problem & $0(0)$ & $0-1$ & No problem \\
\hline 18. Moving around within the home & $0(0)$ & $0-1$ & No problem & $0(0)$ & $0-0$ & No problem \\
\hline $\begin{array}{l}\text { 19. Moving around within buildings other } \\
\text { than home }\end{array}$ & $0(1)$ & $0-2$ & No problem & $0(0)$ & $0-1$ & No problem \\
\hline $\begin{array}{l}\text { 20. Moving around outside the home and } \\
\text { other buildings }\end{array}$ & $1(1)$ & $0-2$ & Mild problem & $0(0)$ & $0-1$ & No problem \\
\hline 21. Using private motorized transportation & $1(1)$ & $0-2$ & Mild problem & $0(0)$ & $0-0$ & No problem \\
\hline 22. Using public motorized transportation & $1(1)$ & $0-2$ & Mild problem & $0(0)$ & $0-0$ & No problem \\
\hline 23. Driving motorized vehicles & $\mathrm{n} / \mathrm{a}$ & 0 ou 9 & $\mathrm{n} / \mathrm{a}$ & $\mathrm{n} / \mathrm{a}$ & 0 ou 9 & - \\
\hline
\end{tabular}

Note: $x( \pm)=$ mean (standard deviation); n/a: not applicable.

The percentage of patients classified as having some form of "problem" (score $\neq 0$ ) in the APP declined significantly after the intervention. The item with the highest percentage of patients that exhibited some type of "problem" at assessment was "transferring oneself while lying down". The percentage of patients who experienced a "problem" for "transferring oneself to the left side while lying down" remained the same after intervention.
At reassessment, no patients experienced any difficulty for the items "kneeling", "standing", "walking short distances", "waking on different surfaces", "moving around within the home" or "using private motorized transportation" (Table 3).

The total score of the APP items declined significantly after the intervention ( $p=0.018)$, with only one patient maintaining the same score. The decline in postintervention score varied between 0 and 34 (Table 4). 
Table 3 - Percentage of patients with some form of "problem" in APP items before and after the intervention ( $n=8$ patients)

\begin{tabular}{|c|c|c|}
\hline \multirow[b]{2}{*}{ APP item } & \multicolumn{2}{|c|}{ Percentage (\%) of patients with a "problem" per item } \\
\hline & Assessment (before intervention) & Reassessment fter intervention) \\
\hline 1. Sitting & 13 & 13 \\
\hline 2. Lying down & 50 & 13 \\
\hline \multicolumn{3}{|l|}{ 3. Roling over } \\
\hline 3.1 To the right & 38 & 13 \\
\hline 3.2 To the left & 38 & 25 \\
\hline \multicolumn{3}{|l|}{ 4. 2. Transferring oneself while lying down } \\
\hline 4.1 To the right & 63 & 38 \\
\hline 4.2 To the left & 50 & 50 \\
\hline 5. Crawling & 50 & 13 \\
\hline 6. Kneeling & 38 & 0 \\
\hline 7. Bending & 50 & 25 \\
\hline 8. Transferring oneself while sitting & 25 & 13 \\
\hline 9. Standing & 38 & 0 \\
\hline 10. Squatting & 50 & 25 \\
\hline 11. Kicking & 25 & 0 \\
\hline 12. Pushing with lower extremities & 50 & 13 \\
\hline 13. Walking short distances & 25 & 0 \\
\hline 14. Walking long distances & 38 & 13 \\
\hline 15. Walking on different surfaces & 25 & 0 \\
\hline 16. Walking around obstacles & 38 & 25 \\
\hline 17. Climbing & 25 & 25 \\
\hline 18. Moving around within the home & 25 & 0 \\
\hline 19. Moving around within buildings other than home & 25 & 25 \\
\hline 20. Moving around outside the home and other buildings & 50 & 25 \\
\hline 21. Using private motorized transportation & 38 & 0 \\
\hline 22. Using public motorized transportation & 38 & 0 \\
\hline 23. Driving motorized vehicles & $\mathrm{n} / \mathrm{a}$ & $\mathrm{n} / \mathrm{a}$ \\
\hline$x( \pm)$ & $36(14)$ & $14(14)^{\star}$ \\
\hline
\end{tabular}

Note: APP $=$ Activity and participation profile; $x( \pm)=$ mean (standard deviation); ${ }^{*} \mathrm{p}<0.0001$ (Wilcoxon test); n/a: not applicable.

Table 4 - Total score for the 25 APP items per patient ( $n=8$ patients) before and after the intervention

\begin{tabular}{|c|c|c|c|}
\hline \multirow[t]{2}{*}{ Patient (No.) } & \multicolumn{2}{|c|}{ Total score } & \multirow[t]{2}{*}{ Score reduction } \\
\hline & Assessment (before intervention) & Reassessment (after intervention) & \\
\hline 1 & 27 & 7 & 20 \\
\hline 2 & 1 & 0 & 1 \\
\hline 3 & 3 & 0 & 3 \\
\hline 4 & 3 & 3 & 0 \\
\hline 5 & 18 & 2 & 16 \\
\hline 6 & 45 & 11 & 34 \\
\hline 7 & 1 & 0 & 1 \\
\hline 8 & 7 & 5 & 2 \\
\hline$x( \pm)$ & $13(16)$ & $4(4)^{\star}$ & 9 \\
\hline
\end{tabular}

Note: APP = Activity and participation profile; $x( \pm)=$ mean (standard deviation); ${ }^{*} \mathrm{p}<0.018$ (Wilcoxon test). 


\section{Discussion}

In the present study, most of the APP items related to mobility based on ICF exhibited a "mild problem" at baseline assessment in a sample of people with PD. A positive effect was observed for these same items following therapeutic exercises associated with music-based RAS, suggesting that the intervention is a promising strategy for improving the functionality of people with PD and controlling the motor symptoms of the disease.

Exercise programs and training strategies play an important role in improving the functionality and participation of individuals with PD and must be chosen based on careful, comprehensive and individualized assessment of the difficulties they experience. ${ }^{29}$ In the present study, we opted for a strategic assessment of the APP by selecting mobility-related activities/participation from the ICF. ${ }^{25}$ We believe that this assessment contributed to a better understanding of the effects of our treatment strategy.

At assessment, three activities obtained scores between 0 and 3 ("no problem" to "severe problem"): "transferring oneself to the right and left while lying down", "transferring oneself while sitting" and "squatting". In a study that investigated women with PD, activities that required consecutive and alternating movements, such as transfers and squatting, were also the most negatively affected by the disease. ${ }^{30}$

In PD, changes in the modulation of basal ganglia caused by dopamine depletion result in less cortical activation, which explains the difficulty executing sequential movements and functional tasks. Additionally, axial rigidity is believed to limit trunk mobility and compromise co-contraction of the trunk and hip muscles, reducing selectivity and motor coordination and hampering functional activities. ${ }^{2,31}$

The only item with scores that varied between 0 and 4 ("no problem" to "complete problem") was "walking long distances". In a cross-sectional study on functionality, walking limitations were reported by $91 \%$ of the individuals with PD in an interview containing items from the ICF. ${ }^{32}$ We believe that this finding may be related to compromised spatiotemporal gait parameters caused by the clinical picture of PD, such as shorter stride length, slower walking speed and increased cadence. Festinating gait and freezing may also be present, associated with postural instability. ${ }^{31,33}$
All the APP items improved to "no problem" after the intervention, except for "transferring oneself to the left while lying down", which remained the same ("mild problem"). The decision to apply the Pro-Parkinson therapeutic exercise program with music-based RAS using a smartphone application may have contributed to improving most of the APP items.

Neuroimaging studies suggest that rhythm perception activates motor structures that are often compromised in PD, such as the premotor cortex and supplementary motor area, basal ganglia and cerebellum. ${ }^{34,35}$ Additionally, a continuous conditioned musical stimulus promotes an important increase in locomotor activity and extracellular dopamine levels in the basolateral amygdala and nucleus accumbens, contributing to the effectiveness of music as a motor stimulus. ${ }^{36}$

The fact that "transferring oneself to the left while lying down" continued to be a "mild problem" after intervention may be related to the protocol's not using RAS for the exercises "rolling over", "bridge" and "upper trunk mobility", which include the mobility needed to perform this activity. Reduced trunk mobility in PD due to axial rigidity is correlated with the difficulty in performing these tasks ${ }^{2}$ and is present in the early stages of the disease. ${ }^{37}$

Another possibility is a relationship between difficulty with this item and the asymmetry of PD symptoms. The side of the body that patients report as being affected by initial symptoms is generally the most compromised, and in the present study, the right side was the most frequently cited. Patients need good motor control on the right side for "transferring oneself to the left side while lying down". Moreover, as a complex motor skill, this activity is considered difficult and requires the combined mobility of several subcomponents, such as the trunk and upper and lower limbs. 5,38

The use of music-based RAS for transfer exercises in particular could contribute to future protocols, with a view to activating specific pathways in different brain motor areas and releasing biochemical mediators such as dopamine. ${ }^{34}$

The intervention had a positive effect on activities related to the exercises used in the therapeutic protocol. The item "walking long distances", whose scores varied between 0 and 4 ("no problem" to "complete problem") at assessment, improved to "no problem". It is believed that this was largely influenced by gait training associated with RAS, since this strategy seems to promote improvement in gait patterns, such as longer strides 
and increased walking speed. ${ }^{17,39}$ The positive effects of RAS on gait were also demonstrated in studies that use cadence training above the level of comfort in patients with PD, ${ }^{12,40}$ adopting a beat rate of $10 \%$ for the music. ${ }^{41}$

At reassessment, no patients experienced any difficulty for the items "kneeling", "standing", "walking short distances", "waking on different surfaces", "moving around within the home" or "using private motorized transportation". The lower limb strengthening exercises associated with RAS, in addition to the balance and proprioception training performed in bed, may have favored this finding, since these tasks improve functionality. ${ }^{42}$ Step training combined with RAS may also have influenced the postural stability and balance needed for these APP items, since these variables can be improved by including musical rhythm in PD treatment, enhancing the overall stability of postural coordination and optimizing motor function and rehabilitation. ${ }^{43,44}$

A study that used RAS only for step training demonstrated a significant improvement in trunk balance and oscillation, which was maintained for longer (8 weeks) when compared to a group not submitted to RAS, indicating this this stimulus prolonged the effects of step training. ${ }^{45}$

The percentage of patients with a "problem" in the "climbing" item remained unchanged post-intervention (25\%), which may be because our protocol did not include an exercise compatible with this activity. Climbing stairs requires significant physical effort ${ }^{46}$ and the skills and time needed to perform it have been linked to functional performance and quality of life in people with PD. Studies have found that interventions aimed at improving execution of this task enhance the functional performance of these patients. ${ }^{46-48}$ Step or stair exercises (climbing up and down) combined with RAS are suggested for future studies.

There was a significant reduction in the total score for the APP items after intervention, with only one patient maintaining the same score. However, it is important to note that the patients studied are constantly monitored, which contributes to good performance. Further research is needed to clarify the effects of an exercise protocol associated with RAS on APP using the ICF, since none that addressed this topic were found. Furthermore, no studies were identified that use ICF items to assess the APP in PD, but rather other instruments commonly applied for functional assessment and included in ICF components. ${ }^{49-51}$
Global scientific production on the topic is still lacking in research that quantitatively applies the ICF in clinical practice. ${ }^{52-54}$ A literature review found only four studies that associated the ICF with PD, in which the ICF domains chosen to classify these individuals were considered effective and suitable for describing functioning and disability in PD. No longitudinal studies were found that compared the ICF before and after intervention as done in this research. ${ }^{55}$

It is important to underscore that this is an original study because it describes the effects of therapeutic exercises associated with personalized music-based RAS, applied via a smartphone app, on the activity and participation profile of people with $\mathrm{PD}$, using a selection of ICF items as an assessment instrument. In terms of limitations, it should be noted that preliminary intervention studies do not have the same rigor as randomized controlled trials, limiting extrapolation of the findings, which should be interpreted with caution. ${ }^{56}$ Anadditional limitation was the inability to use RAS with all the exercises in the protocol.

We hope that this study will foster further in-depth research on the topic and technological development in health for PD, in addition to encouraging the use of the ICF as a tool in planning comprehensive care to improve the quality of life of this population.

\section{Conclusion}

In this study, therapeutic exercises associated with music-based rhythmic auditory stimulation had a positive effect on the Activities and Participation Profile related to mobility of people with Parkinson's disease.

\section{Authors' contributions}

IMA and ITGOG participated in its conceptualization, methodology, data analysis and interpretation, writing of the article, and approval of the final version to be published. KMCS and CAO participated in its conceptualization, methodology, data analysis and interpretation and approval of the final version to be published. CCSAL and MGWSC contributed to its conceptualization, methodology, data interpretation, critical review of the article, and approval of the final version based on their experience with Gerontology and Parkinson's disease. 


\section{References}

1. Sant CR, Oliveira SG, Rosa EL, Sandri J, Durante M, Posser SR. Abordagem fisioterapêutica na doença de Parkinson. Rev Bras Cienc Envelhec Hum. 2008;5(1):80-9. Full text link

2. Artigas NR, Franco C, Leão P, Rieder CR. Instabilidade postural e quedas são mais frequentes em pacientes com doença de Parkinson com pior mobilidade de tronco. Arq. Neuro-Psiquiatr. 2016;74(7):519-23. DOI

3. Organização Mundial da Saúde. Como usar a ClF: um manual prático para o uso da Classificação Internacional de Funcionalidade, Incapacidade e Saúde (CIF): versão preliminar para discussão. Brasília: OMS; 2013. Full text link

4. Di Nubila HBV. Uma introdução à CIF - Classificação Internacional de Funcionalidade, Incapacidade e Saúde. Rev Bras Saude Ocup. 2010;35(121):122-123. DOI

5. Morris ME. Movement disorders in people with Parkinson's disease: a model for physical therapy. Phys Ther. 2000;80(6): 578-97. DOI

6. Ferraz DD, Trippo KV, Duarte GP, Gomes Neto M, Santos $\mathrm{KOB}$, Oliveira Filho J. The effects of functional training, bicycle exercise and exergaming on walking capacity of elderly with Parkinson's disease: a pilot randomized controlled singleblinded trial. Arch Phys Med Rehabil. 2018;99(5):826-33. DOI

7. Canning CG, Sherrington C, Lord SR, Fung VSC, Close JCT, Latt MD, et al. Exercise therapy for prevention of falls in people with Parkinson's disease: A protocol for a randomised controlled trial and economic evaluation. BMC Neurol. 2009; 9:4. DOI

8. Keus S, Munneke M, Graziano M, Paltamaa J, Pelosin E, Domingos $J$, et al. European physiotherapy guideline for Parkinson's disease. Nijmegen, NL: KNGF/ParkinsonNet; 2014. Full text link

9. Tomlinson $\mathrm{CL}$, Herd $\mathrm{CP}$, Clarke CE, Meek C, Patel S, Stowe R, et al. Physiotherapy for Parkinson's disease: a comparison of techniques. Cochrane Database Syst Rev. 2014;2014(6):CD002815. DO।

10. Dreu MJ, van der Wilk ASD, Poppe E, Kwakkel G, van Wegen $\mathrm{EEH}$. Rehabilitation, exercise therapy and music in patients with Parkinson's disease: a metaanalysis of the effects of music-based movement therapy on walking ability, balance and quality of life. Parkinsonism Relat Disord. 2012;18(Suppl 1):S114-9. DOI

11.Yamashita FC, Saito TC, Almeida IA, Barboza NM, Santos SMS. Efetividade da fisioterapia associada à musicoterapia na doença de Parkinson. ConsScientiae Saude. 2012;11(4):677-84. $\mathrm{DOI}$

12. Silva RA, Gondim ITGO, Souza CCB, Silva KMC, Silva LP, Coriolano, MGWS. Treino do passo e da marcha com estimulação auditiva rítmica na doença de Parkinson: um ensaio clínico randomizado piloto. Fisioter Bras. 2017;18(5):589-97. Full text link

13. Jurado-Noboa C. La Musicoterapia Neurológica como modelo de Neurorrehabilitación. Rev Ecuat Neurol. 2018;27(1): 72-9. Full text link

14. Brancatisano O, Baird A, Thompson WF. Why is music therapeutic for neurological disorders? The Therapeutic Music Capacities Model. Neurosci Biobehav Rev. 2020;112:600-15. DOI

15. Côrte B, Lodovici Neto P. A musicoterapia na doença de Parkinson. Cienc Saude Coletiva. 2009;14(6):2295-304. DOI

16. Santos FR, Coronago VMMO. Uso da musicoterapia como terapia alternativa no tratamento da doença de Parkinson. Id on Line Rev Psic. 2017;11(35):341-60. Full text link

17. Ghai S, Ghai I, Schmitz G, Effenberg AO. Effect of rhythmic auditory cueing on parkinsonian gait: A systematic review and meta-analysis. Sci Re8. 2018;8:506. DOI

18. Bella SD, Dotov D, Bardy B, Cock VC. Individualization of music based rhythmic auditory cueing in Parkinson's disease. Ann N Y Acad Sci. 2018;1423(1):308-17. DOI

19. Ministerio da Saúde do Brasil. Secretaria de Atenção à Saúde. Portaria Conjunta n 10, de 31 de outubro de 2017. Aprova o Protocolo Clínico e Diretrizes Terapêuticas da Doença de Parkinson. Brasília: Diário Oficial da União; 2017 Nov 9. Full text link

20. Hoehn MM, Yahr MD. Parkinsonism: onset, progression and mortality. Neurology. 1967;17(5):427-42. DOI

21. Brasil. Resolução $n^{\circ}$ 466, de 12 de dezembro de 2012. Brasília: Diário Oficial da União; 2013 Jun 13. Full text link 
22. Brucki SMD, Nitrini R, Caramelli P, Bertolucci PHF, Okamoto IH. Sugestões para o uso do Mini-exame do estado mental no Brasil. Arq Neuro-Psiquiatr. 2003;61(3B):777-81. DOI

23. Folstein MF, Folstein SE, McHugh PR. "Mini-mental state". A practical method for rading the cognitive state of patients for the clinician. J Psychiatr Res. 1975;12(3):189-98. DOI

24. Beck AT, Ward CH, Mendelson M, Mock J, Erbaugh J. An inventory for measuring depression. Arch Gen Psychiatry. 1961;4(6):561-71. DOI

25. Organização Panamericana de Saúde (OPAS), Organização Mundial de Saúde (OMS). CIF: Classificação Internacional de Funcionalidade, Incapacidade e Saúde [Centro Colaborador da Organização Mundial da Saúde para a Família de Classificações Internacionais]. São Paulo: Edusp; 2003. Full text link

26. Capato TTC, Domingos JMM, Almeida LRS. Versão em português da Diretriz Europeia de Fisioterapia para a doença de Parkinson. São Paulo: OmniFarma; 2015. Full text link

27. Lang JT, Kassan TO, Devaney LL, Colon-Semenza C, Joseph MF. Test-retest reliability and minimal detectable change for the 10-meter walk test in older adults with Parkinson's disease. J Geriatr Phys Ther. 2016;39(4):165-70. DOI

28. Dalton DS, Cruickshanks KJ, Klein BEK, Klein R, Wiley $T L$, Nondahl DM. The impact of hearing loss on quality of life in older adults. Gerontologist. 2003;43(5):661-8. DOI

29. Bouça-Machado R, Maetzler W, Ferreira JJ. What is functional mobility applied to Parkinson's disease? J Parkinsons Dis. 2018;8(1):121-30. DOI

30. Souza A, Barreto MM, Santos SMS. Avaliação da atividade funcional e qualidade de vida em mulheres com doença de Parkinson. Saude Pesqui. 2010;3(2):167-72. Full text link

31. Scalzo PL, Teixeira-Júnior AL. Participação dos núcleos da base no controle do tônus e da locomoção. Fisioter Mov. 2009;22(4):595-603. Full text link

32. Andrade FG, Castaneda L, Mello P, Silveira H. Abordagem da funcionalidade e dos fatores ambientais em pacientes com doença de Parkinson através do checklist da Classificação Internacional de Funcionalidade (CIF). Persp Online Biol Saude. 2012;6(2):30-4. Full text link
33. Morris ME, lansek R, Matyas TA, Summers JJ. The pathogenesis of gait hypokinesia in Parkinson's disease. Brain. 1994;117(5):1169-81. DO।

34. Boso M, Politi P, Barale F, Enzo E. Neurophysiology and neurobiology of the musical experience. Funct Neurol. 2006;21(4):187-91. Full text link

35. Nombela C, Hughes LE, Owen AM, Grahn JA. Into the groove: can rhythm influence Parkinson's disease? Neurosci Biobehav Rev. 2013;37(10 Pt 2):2564-70. DOI

36. Polston JE, Rubbinaccio HY, Morra JT, Sell EM, Glick SD. Music and methamphetamine: conditioned cue-induced increases in locomotor activity and dopamine release in rats. Pharmacol Biochem Behav. 2011;98(1):54-61. DOI

37. Franco CRC, Leão $P$, Townsend R, Rieder CRM. Reliability and validity of a scale for measurement of trunk mobility in Parkinson's disease: Trunk Mobility Scale. Arq Neuropsiquiatr. 2011;69(4):636-41. DOI

38. Schenkman M, Shipp KM, Chandler J, Studenski SA, Kuchibhatla M. Relationships between mobility of axial structures and physical performance. Phys Ther. 1996;76(3): 276-85. DOI

39. Spaulding SJ, Barber B, Colby M, Cormack B, Mick T, Jenkins ME. Cueing and gait improvement among people with Parkinson's disease: a meta-analysis. Arch Phys Med Rehabil. 2013;94(3):562-70. DOI

40. Matsumoto L, Magalhães G, Antunes GL, Pasin CT. Efeitos do estímulo acústico rítmico na marcha de pacientes com doença de Parkinson. Rev Neurocienc. 2014;22(3):404-9. DOI

41. Benoit CE, Bella SD, Farrugia N, Obrig H, Mainka S, Kotz SA. Musically cued gait-training improves both perceptual and motor timing in Parkinson's disease. Front Hum Neurosci. 2014;8:494. DOI

42. Tomlinson CL, Patel S, Meek C, Herd CP, Clarke CE, Stowe $\mathrm{R}$, et al. Physiotherapy intervention in Parkinson's disease: systematic review and meta-analysis. BMJ. 2012;345:e5004. DOI

43. Raglio A, Oasi O. Music and health: what interventions for what results? Front Psychol. 2015;6:230. DOI 
44. Coste A, Salesse RN, Gueugnon M, Marin L, Bardy BG. Standing or swaying to the beat: Discrete auditory rhythms entrain stance and promote postural coordination stability. Gait Posture. 2018;59:28-34. DOI

45. Kadivar Z, Corcos DM, Foto J, Hondzinski JM. Effect of step training and rhythmic auditory stimulation on functional performance in Parkinson patients. Neurorehabil Neural Repair. 2011;25(7):626-35. DOI

46. Chaves CMCM, Mitre NCD, Liberato FA. Efeitos de um programa de fisioterapia em pacientes com doença de Parkinson. Rev Neurocienc. 2011;19(3):484-90. Full text link

47. Goulart F, Santos CC, Teixeira-Salmela LF, Cardoso F. Análise do desempenho funcional em pacientes portadores de doença de Parkinson. Acta Fisiatr. 2004;11(1):12-6. Full text link

48. Rodrigues-de-Paula F, Lima LO; Teixeira-Salmela LF, Cardoso F. Exercício aeróbio e fortalecimento muscular melhoram o desempenho funcional na doença de Parkinson. Fisioter Mov. 2011;24(3):379-88. DOI

49. Ellis T, Cavanaugh JT, Earhart GM, Ford MP, Foreman KB, Fredman $L$, et al. Factors associated with physical behavior in people with Parkinson's disease. Phys Ther. 2011;91(12):183848. DOI

50. King LA, Salarian A, Mancini M, Priest KC, Nutt J, Serdar $A$, et al. Exploring outcome measures for exercise intervention in people with Parkinson's disease. Parkinsons Dis. 2013;2013:572134. DOI
51. Bettecken K, Bernhard F, Sartor J, Hobert MA, Hofmann $M$, Gladow $T$, et al. No relevant association of kinematic gait parameters with Health-related Quality of Life in Parkinson's disease. PLoS One. 2017;12(5):e0176816. DOI

52. Castaneda L, Bergmann A, Bahia L. A Classificação Internacional de Funcionalidade, Incapacidade e Saúde: uma revisão sistemática de estudos observacionais. Rev Bras Epidemiol. 2014;17(2):437-51. DOI

53. Ruaro JA, Ruaro MB, Souza DE, Fréz AR, Guerra RO. Uma visão geral e perfil do uso da CIF no da CIF no Brasil - uma década de história. Rev Bras Fisioter. 2012;16(6):454-62. DO।

54. Castaneda L, Castro SS. Publicações brasileiras referentes à Classificação Internacional de Funcionalidade. Acta Fisiatr. 2013;20(1):29-36. Full text link

55. Vojciechowski AS, Zotz TGG, Loureiro APC, Israel VL. The international classification of functioning, disability and health as applied to parkinson's disease: a literature review. Adv Parkinson's Dis. 2016;5(2):29-40. DOI

56. Abbott JH. The distinction between randomized clinical trials (RCTs) and preliminar feasibility and pilot studies; What they are and are not. J Orthop Sports Phys Ther. 2014;44(8): 555-8. DOI 